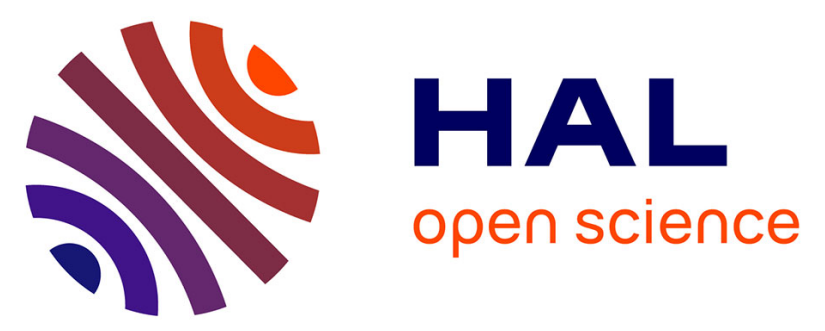

\title{
Alkene Hydroamination via Earth-Abundant Transition Metal (Iron, Cobalt, Copper and Zinc) Catalysis: A Mechanistic Overview
}

Pierre Colonna, Sophie Bezzenine, Richard Gil, Jérôme Hannedouche

\section{- To cite this version:}

Pierre Colonna, Sophie Bezzenine, Richard Gil, Jérôme Hannedouche. Alkene Hydroamination via Earth-Abundant Transition Metal (Iron, Cobalt, Copper and Zinc) Catalysis: A Mechanistic Overview. Advanced Synthesis and Catalysis, 2020, 362 (8), pp.1550-1563. 10.1002/adsc.201901157. hal-03043211

\section{HAL Id: hal-03043211 https://hal.science/hal-03043211}

Submitted on 14 Dec 2020

HAL is a multi-disciplinary open access archive for the deposit and dissemination of scientific research documents, whether they are published or not. The documents may come from teaching and research institutions in France or abroad, or from public or private research centers.
L'archive ouverte pluridisciplinaire HAL, est destinée au dépôt et à la diffusion de documents scientifiques de niveau recherche, publiés ou non, émanant des établissements d'enseignement et de recherche français ou étrangers, des laboratoires publics ou privés. 


\section{Advanced $\Rightarrow$ Synthesis \& Catalysis}

\section{Accepted Article}

Title: Alkene Hydroamination via Earth-Abundant Transition Metal (Fe, Co, $\mathrm{Cu}$ and $\mathrm{Zn}$ ) Catalysis: A Mechanistic Overview

Authors: Pierre Colonna, Sophie Bezzenine-Lafollée, Richard GIL, and Jérôme Hannedouche

This manuscript has been accepted after peer review and appears as an Accepted Article online prior to editing, proofing, and formal publication of the final Version of Record (VoR). This work is currently citable by using the Digital Object Identifier (DOI) given below. The VoR will be published online in Early View as soon as possible and may be different to this Accepted Article as a result of editing. Readers should obtain the VoR from the journal website shown below when it is published to ensure accuracy of information. The authors are responsible for the content of this Accepted Article.

To be cited as: Adv. Synth. Catal. 10.1002/adsc.201901157

Link to VoR: http://dx.doi.org/10.1002/adsc.201901157 


\title{
Alkene Hydroamination via Earth-Abundant Transition Metal (Fe, Co, Cu and Zn) Catalysis: A Mechanistic Overview
}

\author{
Pierre Colonna, Sophie Bezzenine, Richard Gil and Jérôme Hannedouche* \\ Institut de Chimie Moléculaire et des Matériaux d'Orsay (ICMMO), CNRS UMR 8182, Université Paris-Sud, Université \\ Paris-Saclay, 91405 Orsay cedex, France; E-mail: jerome.hannedouche@u-psud.fr.
}

Received: ((will be filled in by the editorial staff))

\begin{abstract}
This review gives a mechanistic overview of the the most relevant advances in the area of alkene (formal) hydroamination promoted by earth-abundant transition metal catalysts involving iron, cobalt, copper and zinc. Focus will be on catalytic systems for which deep investigations have been conducted to elucidate the activation pathway and operating mechanism. The relevant literature has been covered from 2012 until early 2019.
\end{abstract}

Keywords: Earth-abundant 3d transition metal; Hydroamination; Mechanistic studies; Alkenes; Amines.

.

\section{Introduction}

The direct addition of $\mathrm{N}-\mathrm{H}$ amine functionality onto an unsaturated carbon-carbon double bond, the so-called alkene hydroamination reaction, is one of the most appealing route to access valuable nitrogencontaining compounds with $100 \%$ atom efficiency from ubiquitous amines and alkenes. The past few decades have witnessed the development of a plethora of catalysts derived from Group 1-5 (mainly, $\mathrm{Li}, \mathrm{Mg}, \mathrm{Ca}, \mathrm{Ba}, \mathrm{Sc}, \mathrm{Y}, \mathrm{Zr}, \mathrm{Ta}$ ) and noble metals (mainly $\mathrm{Pd}, \mathrm{Rh}, \mathrm{Ir}$ ) to control the selectivities and extend the scope of this reaction. ${ }^{[1]}$ The current growing trend for the incorporation of earth-abundant late transition metals in catalysis has recently offered great developments in addressing some of the selectivity issues and widen the reaction applicability. ${ }^{[\mathrm{lh}-\mathrm{k}]}$ These developments have been accomplished from the exploitation of established activation strategies ${ }^{[2 a, 3 a, 4 a, 5,6,7]}$ and also from the exploration of novel strategies ${ }^{[8,9,10,11]}$ to formally achieve N-H addition on alkenes. This review will outline the most relevant advances in the area of alkene (formal) hydroamination promoted by earthabundant transition metal catalysts involving iron, cobalt, copper and zinc. Focus will be on catalytic systems for which in-depth mechanistic studies have been conducted to elucidate the activation pathway and the operating mechanism. All relevant asymmetric developments to access chiral amines will also be covered. The diverse activation strategies and mechanistic dissimilarity encountered with theses systems will be stressed. The relevant literature has been covered from 2012 until early 2019. For early developments, the reader should refer to previously reported reviews ${ }^{[1 \mathrm{a}, \mathrm{c}, \mathrm{d}, \mathrm{h}, \mathrm{i}, \mathrm{j}, \mathrm{k}]}$ Achievements in the direct addition of electronically biased amines (such as as sulphonamides, carbamates or amides) on unactivated alkenes are out of the scope of this review as such C$\mathrm{N}$ bond formation reactions are today more appropriately called hydroamidation reactions. ${ }^{[1 \mathrm{~g}]}$

Pierre Colonna was born in Dourdan (France) in 1996 and studied physico-chemistry at the Université Paris-Saclay (France). He is currently a Master of science internship's student under the supervision of $\mathrm{Dr}$ Jérôme Hannedouche at the Institut de Chimie Moléculaire et des Matériaux d'Orsay (ICMMO) (Université Paris-Sud/Université Paris-Saclay, France). He is working on cross-dehydrogenating coupling reactions catalyzed by low-coordinate $3 d$ transition metal complexes.

Sophie Bezzenine-Lafollée received her Ph.D. degree from Université Paris VI in 1998. After a postdoctoral stay on asymmetric synthesis with Pr. P. Müller at the University of Geneva, Switzerland, she spent two years in the laboratory of $\mathrm{Pr}$. J. Ardisson at the University of Cergy-Pontoise working on total synthesis. In 2001, she became Maître de Conférence in Orsay University at the Institut de Chimie Moléculaire et des Matériaux d'Orsay (ICMMO). Actually, she works on enantioselective catalysis with rare earth and first row late transition metal complexes. 
Richard Gil studied chemistry at Université Paris-Sud (Orsay, France) where he received his $P h D$ in 1993. His thesis work was under the supervision of Professor JeanClaude Fiaud and dealt with enantioselective palladiumcatalyzed reactions. He then spent one post-doctoral year (19931994) at Imperial College London under the group of Pr. Susan E. Gibson. In 1995, he went to Université de Cergy-Pontoise and became Maître de Conférences in 1996. In 2002, he returned to ICMMO. His research interests include enantioselective reactions catalyzed by rare earth elements.

Jérôme Hannedouche received his PhD degree (2004) from the University of Warwick (UK) under the supervision of Prof. Martin Wills. After a 2-year postdoctoral stay at the Université Catholique de Louvain (Belgium) with Prof. Olivier Riant, he was appointed (2006) at the Institut de Chimie Moléculaire et des Matériaux d'Orsay (ICMMO) (Université Paris- Sud/Université Paris-Saclay, France) as a CNRS fellow researcher. His research interests lie in the development and mechanistic study of novel synthetic methodologies in asymmetric catalysis, mainly for $C-N$ bond formation via hydroamination reaction catalyzed by rare-earth and first-row late transition metal complexes.

\section{Mechanism overview}

Over the years, different approaches have emerged to tackle the issues related to the hydroamination reaction. These approaches rely on preliminary activation of either the alkene or the amine functionality of the reactants by the earth-abundant transition metal. Depending on the catalytic systems involved, the alkene activation pathways feature either olefin $\pi$-coordination to a Lewis acidic metal center $^{[2,3,4]}$ hydrometalation ${ }^{[8,9,10]}$ or hydrogen atom transfer ${ }^{[11]}$ from in situ generated metal-hydride species (Scheme 1, top). The ensuing $\mathrm{C}-\mathrm{N}$ bond formation ends from either nucleophilic attack of the amine moiety on the activated olefin,,${ }^{[2,3,4]}$ umpolung electrophilic amination ${ }^{[8,9,10]}$ or radical ${ }^{[11]}$ coupling. Similarly to Group 1-5 element based catalysts, the amine activation pathway is triggered by the formation of a reactive metal-amido complex from deprotonation of the amine by a basic catalyst (Scheme 1, bottom). ${ }^{[5,6,7]}$ The C-N bond formation arises from olefin insertion into the metal-amido $\sigma$ bond of this complex. ${ }^{[5,6,7]}$

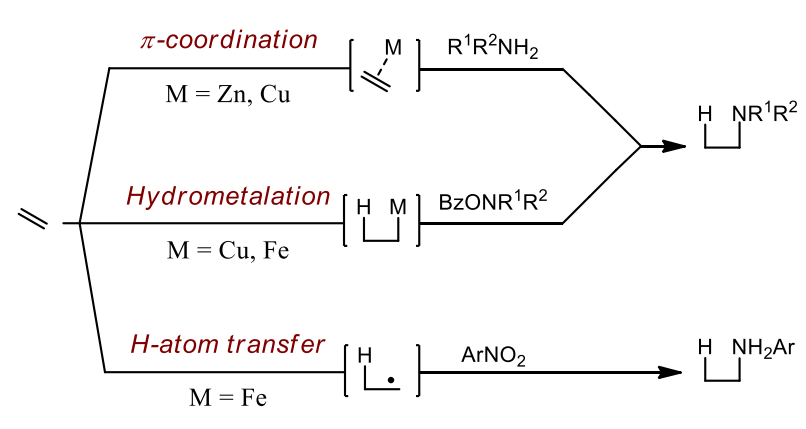

Amine activation pathway

$\mathrm{R}^{1} \mathrm{R}^{2} \mathrm{NH}_{2} \underset{\mathrm{M}=\mathrm{Fe}, \mathrm{Co}, \mathrm{Cu}}{\stackrel{\text { deprotonation }}{\longrightarrow}} \mathrm{M}-\mathrm{NR}^{1} \mathrm{R}^{2} \longrightarrow$

Scheme 1. Mechanism overview of the metal-catalyzed alkene hydroamination processes discussed herein.

\section{Alkene activation pathways}

\section{$3.1 \pi$-coordination}

Among the different methodologies reported in the literature, the most commonly spread mechanism for alkene hydroamination catalyzed by late transition metal-based systems is the olefin-activation mechanism by $\pi$-coordination. For instance, the most active and general among late transition metal-base systems reported so far for the cyclohydroamination of alkenes and primary or secondary amines, th rhodium monocationic system, $\left[\mathrm{Rh}(\mathrm{COD})_{2}\right] \mathrm{BF}_{4} / \mathrm{bis}$ (diethylamino) xantphos ligand, operates in a similan alkene activation pathway as highlighted by detailed mechanistic investigations. ${ }^{[12]} \mathrm{An}$ analogue activation pathway has been demonstrated by extensive mechanistic and theoretical studies for the hydroamination of aminoalkenes catalyzed by [ $\mathrm{Ir}$ (COD)Cl $]_{2} \cdot{ }^{[13]}$ This postulated activation pathway has been at the origin of the initial and following catalyst developments based on copper, ${ }^{[14]}{ }_{i r o n}{ }^{[15]}$ and zinc $^{[2]}$ for alkene hydroamination and related hydroamidation reactions in the burgeoning context of first-row late transition metals. In 2012, the Mandal's group investigated the catalytic application of well-defined methyl-zinc complexes stabilized by a symmetrical $N$-alkylsubstituted phenalenyl ligand in alkene hydroamination (Scheme 2). ${ }^{[3]}$ This study was inspireu by the elegant work of Roesky et al. on the use of aminotroponiminate-liganted and ligand-free methyl zinc complexes for cyclohydroamination of aminoalkenes. ${ }^{[2]}$ As previously reported by the Roesky group, Mandal et al. found that the reaction rate is altered by the ligand $N$-substituent $\left(\mathrm{R}^{4}\right)$ following the trend $\mathrm{Me}\left(\mathbf{1}-\mathbf{Z n}\right.$ with $\left.\mathrm{R}^{4}=\mathrm{Me}\right)<<\mathrm{iPr}$ $(\mathbf{1 a}-\mathbf{Z n}) \leq \mathrm{Cy}(\mathbf{1 b}-\mathbf{Z n})$ and that the catalytic activity is significantly improved in the presence of the $\left[\mathrm{PhNMe}_{2} \mathrm{H}\right]\left[\mathrm{B}\left(\mathrm{C}_{6} \mathrm{~F}_{5}\right)_{4}\right]$ activator (Scheme 2). As noticed for the intramolecular conversion of functionalized primary and secondary aminoalkenes 
into the corresponding 5- and 6-membered rings, the more efficient catalytic systems $\mathbf{1 a - Z n}$ and $\mathbf{1 b}-\mathbf{Z n}$ offer, in the presence of co-catalyst $\left[\mathrm{PhNMe}_{2} \mathrm{H}\right]\left[\mathrm{B}\left(\mathrm{C}_{6} \mathrm{~F}_{5}\right)_{4}\right]$, similar catalytic activities to that of Roesky's methylzinc [N-isopropyl-2(isopropylamino) troponiminato] catalyst (Scheme 2, top). Experimental and computational investigations into the operating mechanism of the reaction were conducted. As anticipated and confirmed by in situ NMR experiment, methyl abstraction of $\mathbf{1 a - Z n}$ by the boron co-catalyst leads to the formation of catalytically active cationic zinc species (Scheme 2, bottom). The reaction rate dependence is first- and inverse order with respect to the catalyst and aminoalkene concentration respectively. Kinetic studies also underline a substantial kinetic isotope effect (KIE) for the cyclohydroamination of primary and secondary aminoalkenes catalyzed by $\mathbf{1 a - Z n}$ and 1b-Zn. DFT calculations reveal that the alkene activation pathway is energetically the most favorable over the energetically inaccessible amine activation pathway. Simultaneously binding of the zinc species to the olefin and amine functionality affords a more stable species that the one exclusively bound to the olefin or amine. A rapid equilibrium involving all these species may be operating. From all of these investigations, it was suggested by the authors that the reaction occurs by first coordination of the olefin to the electrophilic cationic zinc species $\mathbf{A}$, arising from reaction of $\mathbf{1 a - Z n}$ and $\left[\mathrm{PhNMe}_{2} \mathrm{H}\right]\left[\mathrm{B}\left(\mathrm{C}_{6} \mathrm{~F}_{5}\right)_{4}\right]$ (Scheme 2, bottom). ${ }^{[3 \mathrm{a}]}$ The latter is in rapid equilibrium with the putative catalyst resting state $\mathbf{B}$. Nucleophilic attack of the coordinated alkene by the tethered amine provides the ammonium alkylzinc adduct $\mathbf{C}$. Subsequent cleavage of the $\mathrm{Zn}-\mathrm{C} \sigma$-bond by intramolecular turnover-limiting proton transfer generates the product-ligated zinc complex D (Scheme 2, bottom). ${ }^{[3 a]}$ The cyclized hydroamination product is released by the incoming aminoalkene leading to the regeneration of the catalytically competent species A. DFT calculations show that, among the assessed series of $\mathrm{N}$-alkyl-substituted phenalenyl-based zinc complexes, the cationic zinc complex originated from $\mathbf{1 b}-\mathbf{Z n}$ has the greatest stability (evaluated by the HOMO-LUMO energy gap) which is at the origin of the highest activity of this complex. ${ }^{[3 \mathrm{~b}]}$

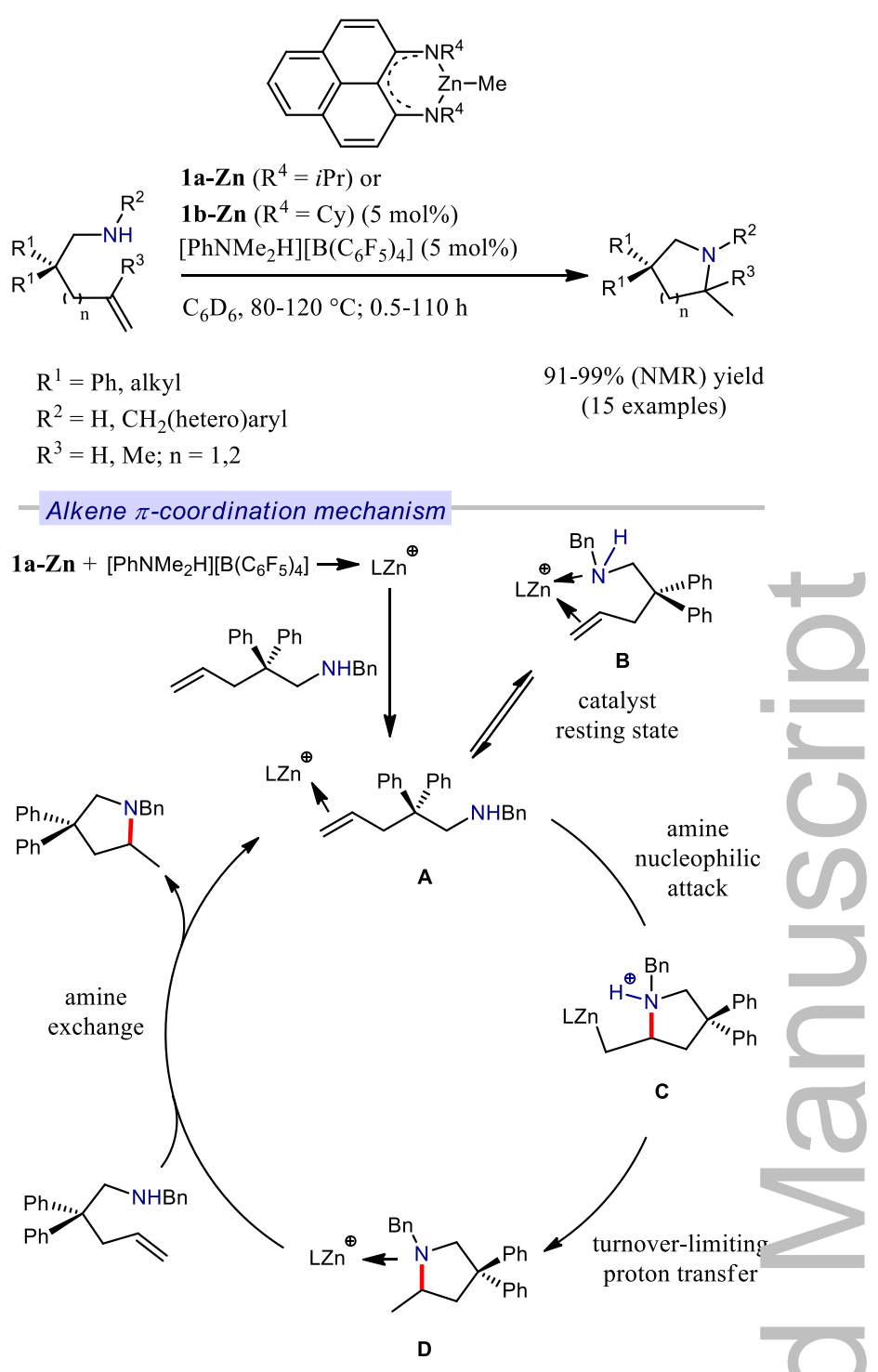

Scheme 2. Cationic zinc-catalyzed exocyclohydroamination of primary and secondary aminoalkenes and its proposed alkene $\pi$-coordination mechanism ( $\mathrm{L}=$ phenalenyl ligand $)$.

In 2017, the group of Monnier and Taillefer described an extension of this olefin-activation strategy to allene-type coumpounds using copper triflate (II) as catalyst. ${ }^{[4 a]}$ This is the first report of copper-promoted hydroamination of terminal allenes and cyclic secondary amines or aniline derivatives, both partners bearing functional groups (Scheme 3) This process affords regio and stereoselectively the corresponding $(E)$-linear allylamines as the only product of hydroamination under mild reaction conditions, but with a large excess of amine. A joint experimental and theoretical mechanistic study with the group of Ciofini and Grimaud smartly identified the catalytically active species as being a cationic copper (I) species. The regio- and stereoselectivities observed for the linear $(E)$-allylamine product was also rationalized. ${ }^{[4 b, c]}$ 


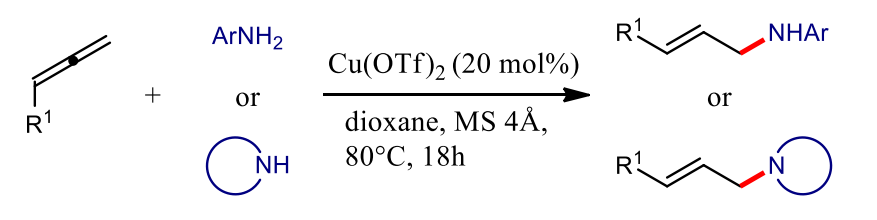

4 equiv 1 equiv $44-88 \%$ yield

$\mathrm{R}^{1}=$ functionalized alkyl, aryl (26 examples)

Scheme 3. Regio- and stereoselective copper(II) triflatecatalysed hydroamination of terminal allenes and cyclic secondary amines or anilines.

\subsection{Hydrometalation}

In 2013, taking advantage of the well-known phosphine copper-hydride chemistry ${ }^{[16]}$ and the electrophilicity ${ }^{[17]}$ of hydroxylamine esters, an original and mechanistically distinct strategy for the $\mathrm{C}-\mathrm{N}$ bond formation from arylalkenes and hydroxylamine esters as amine sources was independently reported by the groups of Buchwald ${ }^{[8]}$ and Miura ${ }^{[9]}$ and Hirano. This novel strategy relying on an umpolung electrophilic amination approach was an astonishing breakthrough in the field of nowcalled formal hydroamination. ${ }^{[18]}$ Both reports highlight that the combination of a chiral biphosphine ligand and a copper(I) or (II) salt in the presence of a hydrosilane reagent are particularly efficient for the regio- and enantioselective intermolecular formal hydroamination of arylalkenes and $O$ - benzoylhydroxylamines. ${ }^{[8,9]}$ The original Buchwald combination $\left((R)\right.$-DTBM-SEGPHOS $\left((R)-\mathbf{L}_{\mathbf{1}}\right)$ / $\left.\mathrm{Cu}(\mathrm{OAc})_{2} / \mathrm{HSiMe}(\mathrm{OEt})_{2}\right)$ has a wider scope than the Miura and Hirano combination (( $S, S)$-Me-Duphos or $(R, R)$-Ph-BPE) / $\mathrm{CuCl} /$ diethoxymethylsilane / LiOtBu) and is currently the most applied combination $^{[8,19]}$ The former is indeed efficient for the preparation of a plethora of chiral tertiary amines (chiral branched amines, $\alpha$-amino-silanes and $\alpha$ boronic acids, $\beta$-chiral amines) from a range of alkene derivatives (functionalized styrenes, cis/trans$\beta$-substituted and $\beta$ - $\beta$-substituted arylalkenes, vinylsilanes, alkenyl 1,8-diaminonaphthyl boronates and 1,1-dialkyl-substituted alkenes) in good to excellent yields and with high enantiomeric excesses ( Scheme 4). ${ }^{[8,20]}$ It was noted that both $(E)$ - and $(Z)$ vinylsilanes provide the same enantiomer, but $(E)$ isomers are obtained with higher ee values and with faster reaction rates than the corresponding ( $Z$ ) isomers. ${ }^{[20 b]}$

The scope of this $\mathrm{Cu}-\mathrm{H}$-based methodology was further expanded to include the formation of chiral secondary amines and the conversion of highly challenging internal alkenes ${ }^{[22]}$ in high yields. ${ }^{[21]}$ This scope extension relies on the crucial use of the more electron-rich 4-(dimethylamino)benzoate group on the electrophilic amine partner instead of the previously employed benzoate group ( Scheme 4). 


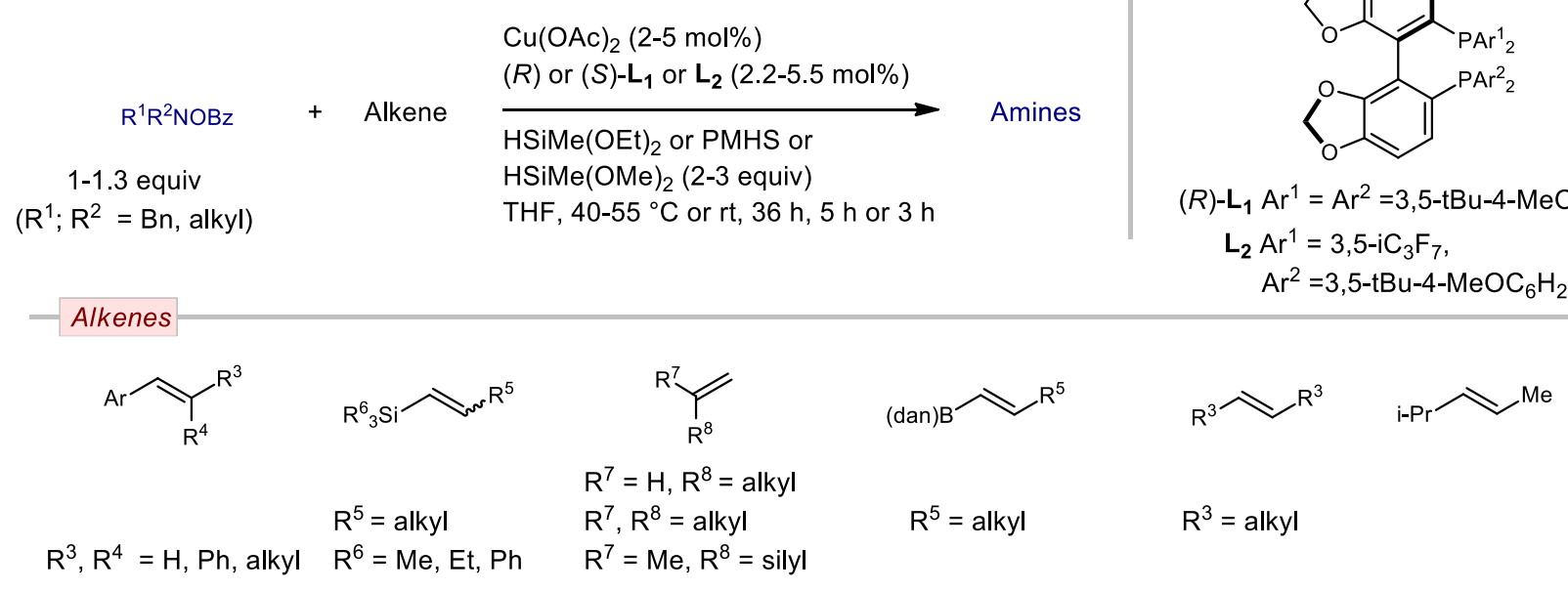

Tertiary and Secondary Amines

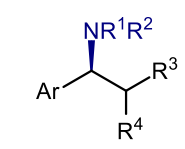

$77-98 \%$ yield, $86-99 \%$ ee (21 examples)

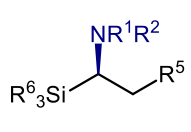

\section{$73-99 \%$ yield,} $84->99 \%$ ee (24 examples)<smiles>CCC(C)CC(C)C</smiles>

$70 \%$ yield, e $99 \%$ ee

$$
\mathrm{R}^{3}{\stackrel{(}{N} \mathrm{R}^{1} \mathrm{R}^{2}}^{\mathrm{R}^{3}}
$$
$\begin{array}{ll}50-94 \% \text { yield, c } & \mathrm{R}^{1}=\mathrm{Ar}, 50-94 \% \text { yield, }{ }^{\mathrm{g}} \\ 97-99 \% \text { ee } & 83-99 \% \text { ee }\end{array}$ (25 examples)
(22 examples)
$R_{R^{8}}^{7} \cdot \overbrace{N R^{1} R^{2}}$

$17-99 \%$ yield,

$7-99 \%$ ee

(44 examples)

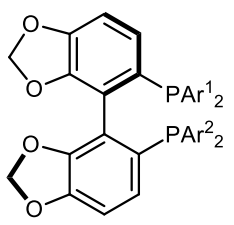

R) $-\mathrm{L}_{1} \mathrm{Ar}^{1}=\mathrm{Ar}^{2}=3,5-\mathrm{tBu}-4-\mathrm{MeOC}_{6} \mathrm{H}_{2}$

$\mathrm{L}_{2} \mathrm{Ar}^{1}=3,5-\mathrm{iC}_{3} \mathrm{~F}_{7}$,

$\mathrm{Ar}^{2}=3,5-\mathrm{tBu}-4-\mathrm{MeOC}_{6} \mathrm{H}_{2}$

Schiff Bases and Primary Amines with $R^{1} R^{2} N O B z=1,2-$ benzisoxazole<smiles>[R]C[C@H]([Al])N=Cc1ccccc1OC</smiles>

$63-87 \%$ yield, $92-99 \%$ ee $(18 \text { examples })^{\mathrm{h}}$

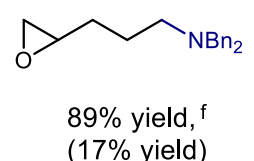

( $17 \%$ yield)<smiles>[R7]CC([18OH])[13CH2][13CH]</smiles>

$17-81 \%$ yield, ${ }^{\mathrm{b}}$ $76-99 \%$ ee (23 examples)<smiles>[R]CC(N)[Al]</smiles>

$59-92 \%$ yield,, $\mathrm{d} d$ $92-99 \%$ ee (25 examples)<smiles>CCC(C)OC(=O)c1ccc(OCCCCNC(=O)c2ccccc2)cc1</smiles>
(29\% yield)

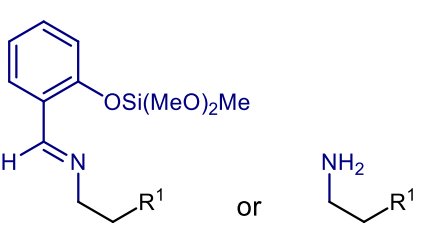

$65-86 \%$ yield $(8 \text { examples })^{\mathrm{h}}$

Scheme 4. Regio- and enantioselective biphosphine-CuH-catalyzed formal hydroamination of alkene derivatives and electrophilic amines. a) all reactions run with $(R)$ or $(S)$-L1 unless otherwise stated. b) with $\mathrm{LiO} t \mathrm{Bu}(4 \mathrm{equiv})$. c) with $\mathrm{R}^{2} \mathrm{NHOCO}_{2}\left(p-\mathrm{NMe}_{2} \mathrm{C}_{6} \mathrm{H}_{4}\right)$. d) with $\mathrm{PPh}_{3}\left(4.4-8.8\right.$ mol\%). e) regioselectivity = 82:18. f) with $( \pm)-\mathbf{L}_{2}$ instead of $\left.( \pm)-\mathbf{L}_{\mathbf{1}} . \mathrm{g}\right)$ with ${ }^{t} \mathrm{BuOH}$ (1 equiv) and $\mathrm{PPh}_{3}(2-6 \mathrm{~mol} \%)$. h) conversion of the chiral Schiff bases into the primary amines without ee erosion: $\mathrm{NH}_{2} \mathrm{OH} . \mathrm{HCl}, \mathrm{MeOH}$. dan = 1,8-diamononaphthyl.

In-depth experimental studies have been conducted on the $\mathrm{C}-\mathrm{N}$ bond formation reaction of styrenes and $O$-benzoyl- $N, N$-dialkyl-hydroxylamine catalyzed by the system $\left.\left((R)-\mathbf{L}_{1}\right) / \mathrm{Cu}(\mathrm{OAc})_{2} / \mathrm{HSiMe}(\mathrm{OEt})_{2}\right) .{ }^{[23]}$ These studies, completed by computational investigations done with a structurally simplified combination ((1,2-bis(diphenylphosphino)benzene / $\left.\mathrm{Cu}(\mathrm{OAc})_{2} / \mathrm{LiOtBu} / \mathrm{Me}_{3} \mathrm{SiH}\right)$ and electrophilic amine $\left(\mathrm{Me}_{2} \mathrm{NOBz}\right),{ }^{[24]}$ support the mechanistic picture displayed in Scheme 5 as proposed by the authors. The initial reaction of the enantiopur biphosphine ligand $\mathbf{L}_{\mathbf{1}} / \mathrm{Cu}(\mathrm{OAc})_{2}$ with the hydrosilane reagent leads, after reduction and transmetalation, in the generation of catalytically relevant $\mathbf{L}_{1} \mathrm{Cu}(\mathrm{I})-\mathrm{H}$ being monomeric as suggested by the linear relationship $e_{\text {prod }}=\mathrm{f}\left(\mathrm{ee}_{\text {ligand }}\right){ }^{[23]}$ Nevertheless, the measurement of an apparent fractional order dependence of the reaction rate on the concentration in metal evokes a putative equilibrium of $\mathbf{L}_{1} \mathrm{Cu}(\mathrm{I})-\mathrm{H}$ with its dimer or higherorder species or aggregates. ${ }^{[25]}$ The $\mathrm{Cu}-\mathrm{H} \sigma$-bond is subsequently engaged in a regioselective alkene 2,1- 
migratory insertion with styrene via a four-center planar transition state resulting in the formation of an alkyl copper(I) species $\mathbf{E}$ ( Scheme 5). This hydrometalation step is irreversible and enantiodetermining as suggested by deuterium-labelling experiments and the linear free energy relationships between the Hammet electronic parameters of parasubstituted styrenes and the measured ee values. Subsequent N-O bond cleavage of the amine reagent through intramolecular $\mathrm{S}_{\mathrm{N}} 2$ displacement promoted by species $\mathbf{E}$ leads to the formation of species $\mathbf{F}$. ${ }^{[23]}$ An easy and stereoretentive reductive elimination liberates the formal hydroamination product by $\mathrm{C}-\mathrm{N}$ bond formation and provides $\mathbf{L}_{1} \mathrm{CuOCOAr}$. The latter should be the resting state of the catalyst as shown by MS and NMR studies. ${ }^{[23]}$ Subsequent transmetalation between $\mathbf{L}_{1} \mathrm{CuOCOAr}$ and the hydrosilane regenerates the catalytically competent $\mathbf{L}_{1} \mathrm{Cu}(\mathrm{I})-\mathrm{H}$. From a linear Hammet correlation between the reaction rate and the electronic parameters of the para-substituents of the aromatic ring of the amine, it was demonstrated that the reaction rate increases with the electronic richness of the electrophilic amine. ${ }^{[23]}$ Further studies have shown that the reaction rate is not influenced by the styrene para-substitutent and displays a first-order dependence on silane concentration and a zero-order dependence on styrene and amine concentration. ${ }^{[23]}$ These observations are consistent with the transmetalation step being ratedetermining.

On the basis of these mechanistic investigations, the observation of a better efficiency of electrophilic amine partners bearing more-electron rich esters may arise from their enhanced ability to restore the active $\mathbf{L}_{1} \mathrm{Cu}(\mathrm{I})-\mathrm{H}$ during the rate-limiting transmetalation and their diminished non-productive degradation by the catalyst as demonstrated by DFT studies ( Scheme 5). ${ }^{[24]}$ Electronic stabilization of copper species $\mathbf{E}$ by the neighbouring aryl (or silyl) group and formation of a less sterically hindered alkylcopper intermediate rationalize the observation of a Markovnikov and anti-Markovnikov selectivity for arylalkenes (and vinylsilanes) and linear alkenes respectively. Examination of the through-bond and through-space interactions between the $\mathrm{Cu}(\mathrm{I})-\mathrm{H}$ catalyst ligated to diverse biphosphine and alkylalkenes by DFT calculations shows that the superior reactivity noted with the bulky ligand DTBM-SEGPHOS emanates principally from a better stabilization of the hydrocupration transition state via superior dispersion interactions from the tert-butyl substituent of the phosphine and the alkyl substituent of the alkene. ${ }^{[23 \mathrm{~b}]}$ Indeed, for terminal and internal alkenes and in contrast to arylalkenes, the ratelimiting step is the hydrocupration step. ${ }^{[23]}$ Additionally, the high enantiofacial discrimination of the olefin during the hydrometalation step originates from the spatial orientation of the tertbutylsubstituted aryl group of the biphosphine ligand as suggested by DFT studies. ${ }^{[21 a]}$ The understanding of the substrate-ligand interactions was exploited further to design a more efficient biphosphine ligand for this CuH-catalyzed transformation. ${ }^{[26]}$ An iterative ligand design approach lead to the identification of ligand L2 (SEGFAST; Scheme 4) as affording a significantly more active copper-hydride catalyst than the previous optimal ligand $\mathbf{L}_{\mathbf{1}}$. Indeed, $\mathbf{L}_{\mathbf{2}}$ provides a 62-fold rate increase compared to $\mathbf{L}_{\mathbf{1}}$ in the antiMarkovnikov hydroamination of terminal alkylalkenes and $\mathrm{Bn}_{2} \mathrm{NOBz}$ (Scheme 3). ${ }^{[26]}$ The alliance of both $3,5-i \mathrm{C}_{3} \mathrm{~F}_{7}$ and $3,5-t \mathrm{Bu}-4-\mathrm{MeOC}_{6} \mathrm{H}_{2}$ substituents was crucial to achieve the proper balance of stability and reactivity at the catalyst.

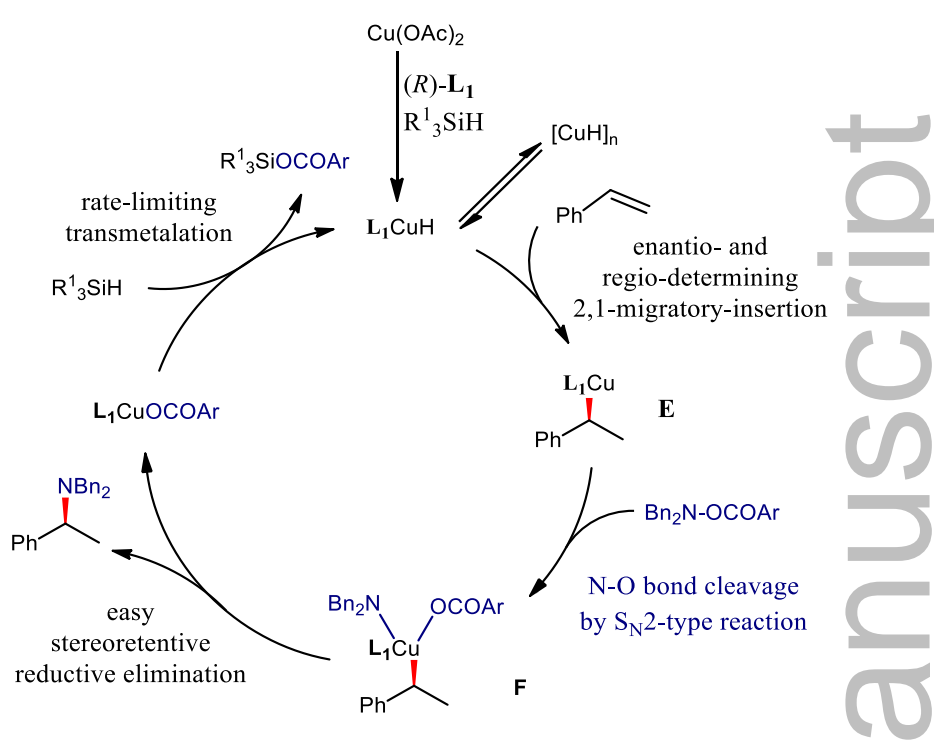

Scheme 5. Proposed mechanism for DTBMSEGPHOS.CuH-catalyzed hydroamination of styrene and $\mathrm{Bn}_{2}$ NOCOAr proceeding by alkene hydrometalation $\left(\mathbf{L}_{1}\right.$ (R)-DTBM-SEGPHOS).

This mechanistic understanding led, through structure optimizations of the silane, amine transfer agent and use of additives $\left({ }^{t} \mathrm{BuOH}, \mathrm{PPh}_{3}\right)$ to noteworthy enhancement of the scope, efficiency and practicality of the $\mathrm{CuH}-$ methodology. ${ }^{[23 a, 27,28]}$ For instance, the synthesis of enantioenriched $\mathrm{N}$ arylamines could be achieved by the addition of tBuOH (1 equiv) and $\mathrm{PPh}_{3}$ in catalytic amount to the reaction medium. ${ }^{[28 \mathrm{a}]}$ The employ of 1,2benzisoxazole as electrophilic amine partner equivalent to ammonia affords a practical access to enantioenriched $\alpha$-branched and linear primary amines under mild reaction conditions (Scheme 4). [28b] The chiral Schiff bases products obtained through this procedure can be quantatively converted into the corresponding primary amines without enantiomeric excess erosion.

Among the earth-abundant transition metal catalysts covered herein, the DTBM-SEGPHOS-CuH hydroamination methodology offers the wider synthetic utility and should be the methodology of choice for the preparation of a plethora of (chiral) amines classes (e.g linear alkylamines, enamines, $\alpha-$, $\gamma$-, or $\delta$-chiral branched alkylamines, chiral 1,3-amino alcohols) from easily available starting materials with 
high levels of chemo-, regio-, and stereocontrol. ${ }^{[21,}$ 27,28]

In 2014, an analogue electrophilic amination strategy was described for the regioselective Markovnikov hydroamination of aromatic olefins and hydroxylamine esters using the combination iron(II) dichloride/2,6-diiminopyridine as precatalyst and a cyclopentylmagnesium bromide as reducing agent (Scheme 6). ${ }^{[10]}$ However, the scope of this iron-based protocol is not as broad as that of the $\mathrm{CuH}$ methodology as it is inefficient for the conversion of $\alpha$ - and $\beta$-methylstyrenes, $p$ - $\mathrm{Cl}$ and $p$ - $\mathrm{CF}_{3}$-styrene and aliphatic terminal alkenes. Mechanistically speaking, the authors proposed that a $\mathrm{Fe}-\mathrm{H}$ species is generated (from $\mathrm{FeCl}_{2}$ and Grignard reagent) and subsequently engaged in a regioselective alkene 2,1-migratoryinsertion. Electrophilic amination of the ensuing alkyl iron species leads to $\mathrm{C}-\mathrm{N}$ bond formation.

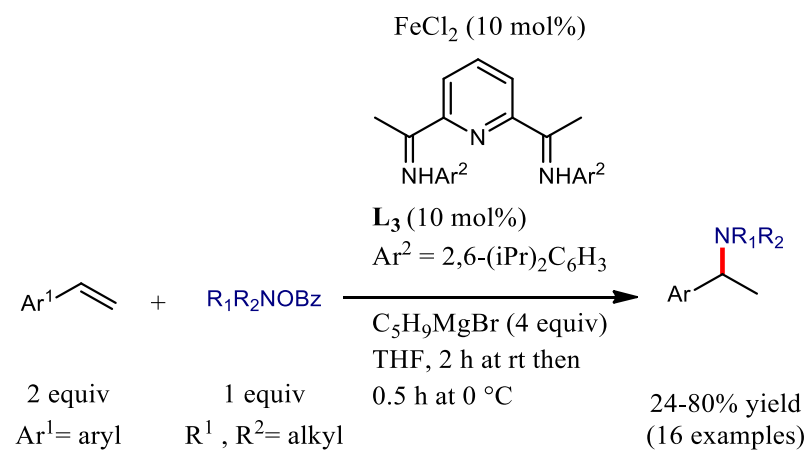

Scheme 6. Regioselective iron-catalyzed Markovnikov hydroamination of aromatic olefins and hydroxylamine esters.

\subsection{H-atom transfer}

In 2015, the group of Baran described the formal hydroamination of nitroarenes and alkenes using an iron-based methodology which follows a different activation mechanism from alkene $\pi$-coordination or hydrometalation. ${ }^{[11]}$ From their expertise on the $\mathrm{H}$ atom transfer (HAT) promoted by $\mathrm{Fe}$ (III)-H for $\mathrm{C}-\mathrm{C}$ bond radical formations from alkenes ${ }^{[29]}$ and some literature precedent ${ }^{[30]}$, the group reports a practical process based on iron hydride chemistry for the preparation of secondary (hetero)aryl amines substituted by secondary or tertiary alkyl from nitro(hetero)arenes and mono and polysubstituted alkenes by $\mathrm{C}-\mathrm{N}$ bond formation (Scheme 7 , top). ${ }^{[11 \text {, }}$ ${ }^{231]]}$ A wide range of hindered secondary (hetero)aryl amines has been synthesized from alkenes and nitroarenes through the use of $\mathrm{Fe}(\mathrm{acac})_{3}(30 \mathrm{~mol} \%)$ in the presence of an excess of $\mathrm{PhSiH}_{3}$ (2-3 equivalents). The optimal operating conditions lead to the isolated amines in low to good yields with exclusive Markovnikov selectivity (Scheme 7, top). ${ }^{[11]}$ In addition to its air and moisture compatibility, this procedure offers a remarkable opportunity for further derivatizations orthogonally to the conventional $\mathrm{C}-\mathrm{N}$ bond formation methods. Indeed, this methodology has a wide tolerance for functional groups such as amide, amine, alcohol, thioether, ketone, halide, nitrile, triflate and boronic acid. No or low yields of hydroamination product are obtained with nitroalkanes, leading to a restriction of the methodology to nitro(hetero)arenes with the exception of $\alpha$-substituted styrenes, 2-nitropyridines, nitroimidazoles and nitrophenyl bearing ortho-esters or free alcohol or thiol. ${ }^{[11]}$ From control experiments and literature background, ${ }^{[32]}$ the authors propose that the catalytic cycle follows the general pathway of Scheme 7 (bottom). ${ }^{[11]}$ This putative mechanism explains the formation of the desired hydroamination products such as amino (hetero)arenes (from the reduction of nitro (hetero)arenes) but also the main by-products such as $\mathrm{N}, \mathrm{O}$-alkylated products $\mathbf{H}$. The initiation step is the in situ formation of the species $\left[\mathrm{Fe}^{\mathrm{n}}\right]-\mathrm{H}$ from $\mathrm{Fe}(\mathrm{acac})_{3}$ and $\mathrm{PhSiH}_{3}$ in $\mathrm{EtOH}^{[33]}$ From the depth experimental and computational studie conducted on the related iron-catalyzed alkene crosscoupling reaction by the groups of Baran, Poli and Holland, ${ }^{[34]}$ one could speculate that the species $\left[\mathrm{Fe}^{\mathrm{n}}\right]$ $\mathrm{H}$ is an unobserved iron(III)-H species. This hydride species reduces both the nitro(hetero)arene and the substituted alkene into the corresponding nitroso(hetero)arene and alkyl radical intermediate respectively by regioselective HAT. After this reduction step, the presumed metallic species would be $\left[\mathrm{Fe}^{\mathrm{n}-1}\right]$ (Scheme 7, bottom). ${ }^{[11]}$ The presence of $\mathrm{ArNH}_{2}$ isolated as by-product arises from further reduction of the nitroso species by $\left[\mathrm{Fe}^{\mathrm{n}}\right]-\mathrm{H}$. Reaction of the nitrosoaryl species with one and tw equivalents of the alkyl radical would form the oxygen-centered radical $\mathbf{G}$ and the $N, O$-dialky compound $\mathbf{H}$ respectively. $\mathbf{G}$ may then undergo monoelectronic reduction by $\left[\mathrm{Fe}^{\mathrm{n}-1}\right]$ to yield the corresponding hydroxylamine anion (Scheme 7, bottom). ${ }^{[1]}$ The latter is converted to the desired hydroamination product after ethanolysis and second monoelectronic reduction regenerating the $\left[\mathrm{Fe}^{\mathrm{n}}\right]^{+}$ cationic species. In the related iron-catalyzed crosscoupling reaction of alkenes and acrylates, these electron transfer-proton transfer sequences that deliver the addition product have been demonstrated to be a concerted proton-coupled electron transfer. ${ }^{[34 b]}$ The authors also suggest that hydroxylamine may also be the result of a hydrogen transfer process between the $\left[\mathrm{Fe}^{\mathrm{n}}\right]-\mathrm{H}$ species and G. ${ }^{[11]}$ The isolated secondary product $\mathbf{H}$ resulting from the double alkylation is converted to the formal hydroamination compound by $\mathrm{Zn} / \mathrm{HCl}$ treatmen (Scheme 7, bottom) ${ }^{[11]}$ Control experiments have clearly established that iron is involved in the activation of both reaction partners (alkene and nitroarene) and that nitroso (hetero)arenes derivatives and hydroxylamines, and not amino(hetero)arenes, are part of the productive process. ${ }^{[11]}$ 

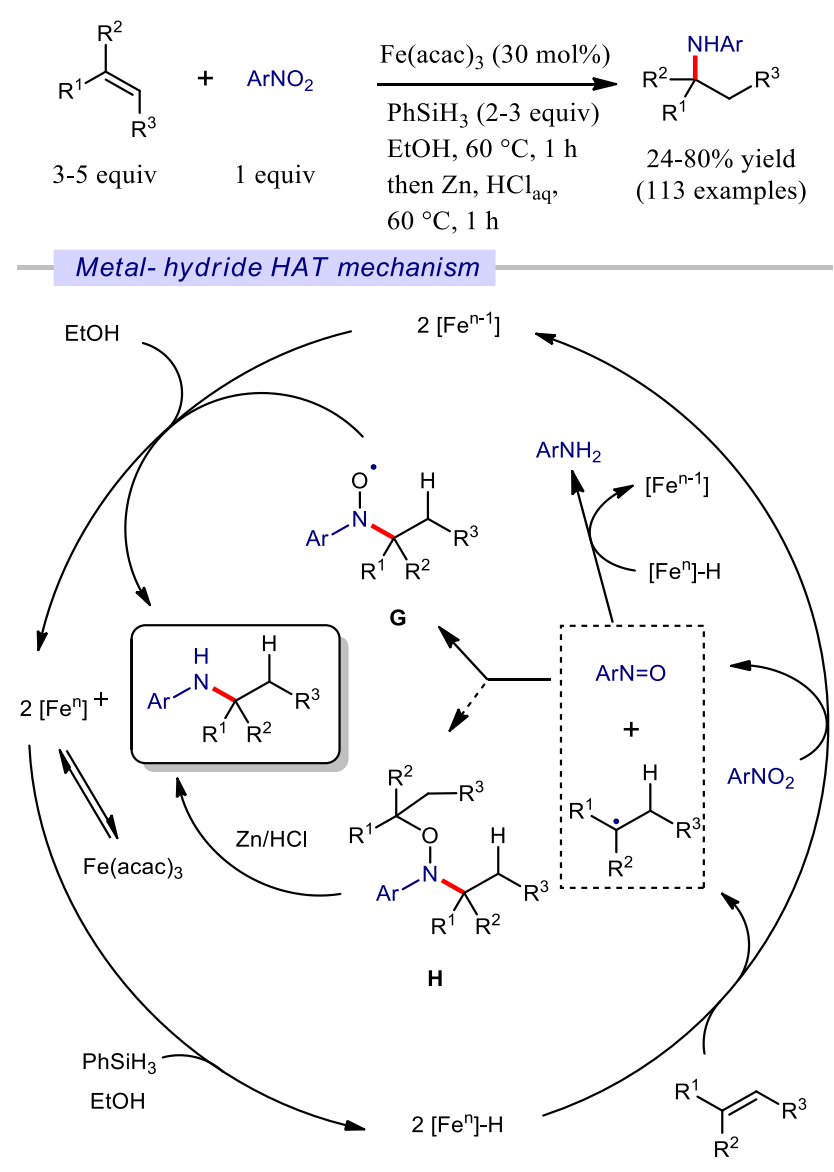

Scheme7. Proposed metal-hydride H-atom transfer (HAT) mechanism of iron-promoted formal hydroamination of nitro(hetero)arenes and (poly)substituted alkenes.

The groups of Thomas and Shaver and the group of Shenvi have independently improved this ironhydride protocol from respectively the use of an amine-bis-(phenolate)iron(III) complex (instead of $\left.\mathrm{Fe}(\mathrm{acac})_{3}\right)$ and isopropoxy(phenyl)silane ${ }^{[35]}$ (instead of phenylsilane). ${ }^{[36]}$ Under these conditions, the reaction can be run at ambient temperature and under lower catalyst loading than the Baran's original report.

\section{Amine deprotonation pathway}

The activation pathway by initial amine deprotonation is mainly encountered in hydroamination with basic catalysts based on Group $1-5$ elements. $^{[1]}$ In the last few years, this activation pathway was extended to earth-abundant, first-row late transition metals in the objective to develop more functional tolerant and sustainable hydroamination catalysts for the cyclization of electronically unbiased primary amines. ${ }^{[5,6,7]}$ In 2014 , this activation mode was employed to develop an unreported iron-based methodology for alkene hydroamination of unprotected primary amines using well-defined low coordinate $\beta$-diketiminatoiron(II) alkyl complexes as catalysts. ${ }^{[5]}$ Stimulated by previous works, ${ }^{[37]}$ the group of Hannedouche has indeed explored the reactivity of theses complexes in the cyclohydroamination of primary aminoalkenes (Scheme 8, top). They demonstrated that the isolated $\mathrm{C}_{2}$-symmetric $\beta$-diketiminatoiron(II) alkyl complex 2a-Fe was an efficient structurally-defined catalyst for the selective hydroamination of primary amines tethered to alkenes, leading to the formation of 5- and 6-membered heterocycles in good to excellent yields (Scheme 8, top). ${ }^{[5]}$ This methodology is however not suitable for to the cyclohydroamination of substrates without a geminal disubstitution on the tether or with 1,2-dialkyl-substituted alkenes. ${ }^{[5]}$ In their preliminary study, ${ }^{[5]}$ the authors highlight that the addition of a catalytic amount of cyclopentylamine enhances the reaction selectivity in favor of the hydroamination product (versus the oxidative products) from 83\% (without cyclopentylamine) to $96 \%$. However, this selectivity enrichment was done at the expense of the reaction rate. More recently, a combined experimental and computational mechanistic study of this transformation promoted by catalyst $\mathbf{2 a - F e}$ (without cyclopentylamine) was undertaken. ${ }^{[3]}$ Kinetic analysis of the cyclohydroamination reaction of 2,2-diphenylpent-4-en-1-amine provides the empirical second-order rate law $\mathrm{v}=\mathrm{k}[\mathbf{2 a}-$ Fe $]^{1}[\text { aminoalkene }]^{1}$, a primary $\mathrm{KIE}\left(k_{\mathrm{H}} / k_{\mathrm{D}}\right)$ of 2.7 $\left(90^{\circ} \mathrm{C}\right)$ and the activation entropy value of $\Delta S^{\ddagger}=-$ $13.4 \mathrm{cal} . \mathrm{mol}^{-1} \cdot \mathrm{K}^{-1}$. These data suggest a highly-order transition state associated with the turnover-limiting step of the catalytic cycle involving the participation of a single adducted aminoalkene and the breaking of a N-H bond. ${ }^{[38]}$ The formation of iron amido complexes I (I_Me and I_Ph), isolated an. characterized as centrosymmetric amido-bridged dimers $[\mathbf{I}]_{2}$, advocate the amine deprotonatio pathway by the alkyl catalyst (Schemes 8 , bottom and 9). Additionally, the formation of insertive products from direct reactivity of isolated dimer [I_Ph $]_{2}$ without the assistance of an additional proton source and the syn-stereochemistry of the cyclisation are in favor of a C-N bond formation proceeding by alkene migratory-1,2-insertion via a stepwise $\sigma$ insertive mechanism. ${ }^{[38]}$ This insertive type mechanism has been previously proposed for hydroamination reactions catalyzed by rare earth and alkaline complexes. ${ }^{[39]}$ The catalytic efficiency of complex [I_Ph $]_{2}$ was similar to complex 2a-Fe suggesting the participation of the latter in the catalytic cycle. ${ }^{[5]}$ The detailed computational survey of the conceivable mechanistic avenues for the hydroamination pathway suggests that an alternative concerted pathway is less favored in the presence of a more kinetically accessible $\sigma$-insertive mechanism. ${ }^{[38]}$ This concerted pathway evolving concomitant $\mathrm{C}$ $\mathrm{N} / \mathrm{C}-\mathrm{H}$ bond formation via a multi-center transition state structure, was put forward as a distinct operating hydroamination mechanism for some rare-earth-, alkaline- and Group 4-based catalysts. ${ }^{[39]}$ 

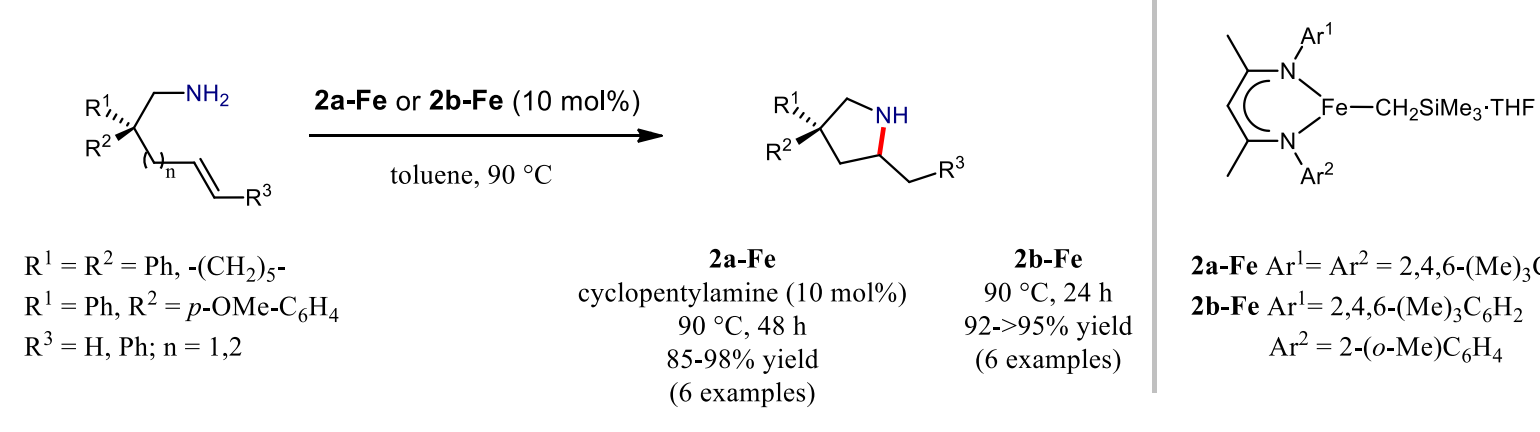

$$
\begin{aligned}
& \mathrm{R}^{1}=\mathrm{R}^{2}=\mathrm{Ph},-\left(\mathrm{CH}_{2}\right)_{5^{-}} \\
& \mathrm{R}^{1}=\mathrm{Ph}, \mathrm{R}^{2}=p-\mathrm{OMe}-\mathrm{C}_{6} \mathrm{H}_{4} \\
& \mathrm{R}^{3}=\mathrm{H}, \mathrm{Ph} ; \mathrm{n}=1,2
\end{aligned}
$$
$2 \mathrm{~b}-\mathrm{Fe}$ $2->95 \%$ yield (6 examples)
2a-Fe $\mathrm{Ar}^{1}=\mathrm{Ar}^{2}=2,4,6-(\mathrm{Me})_{3} \mathrm{C}_{6} \mathrm{H}_{2}$
2b-Fe $\mathrm{Ar}^{1}=2,4,6-(\mathrm{Me})_{3} \mathrm{C}_{6} \mathrm{H}_{2}$
$\mathrm{Ar}^{2}=2-(o-\mathrm{Me}) \mathrm{C}_{6} \mathrm{H}_{4}$

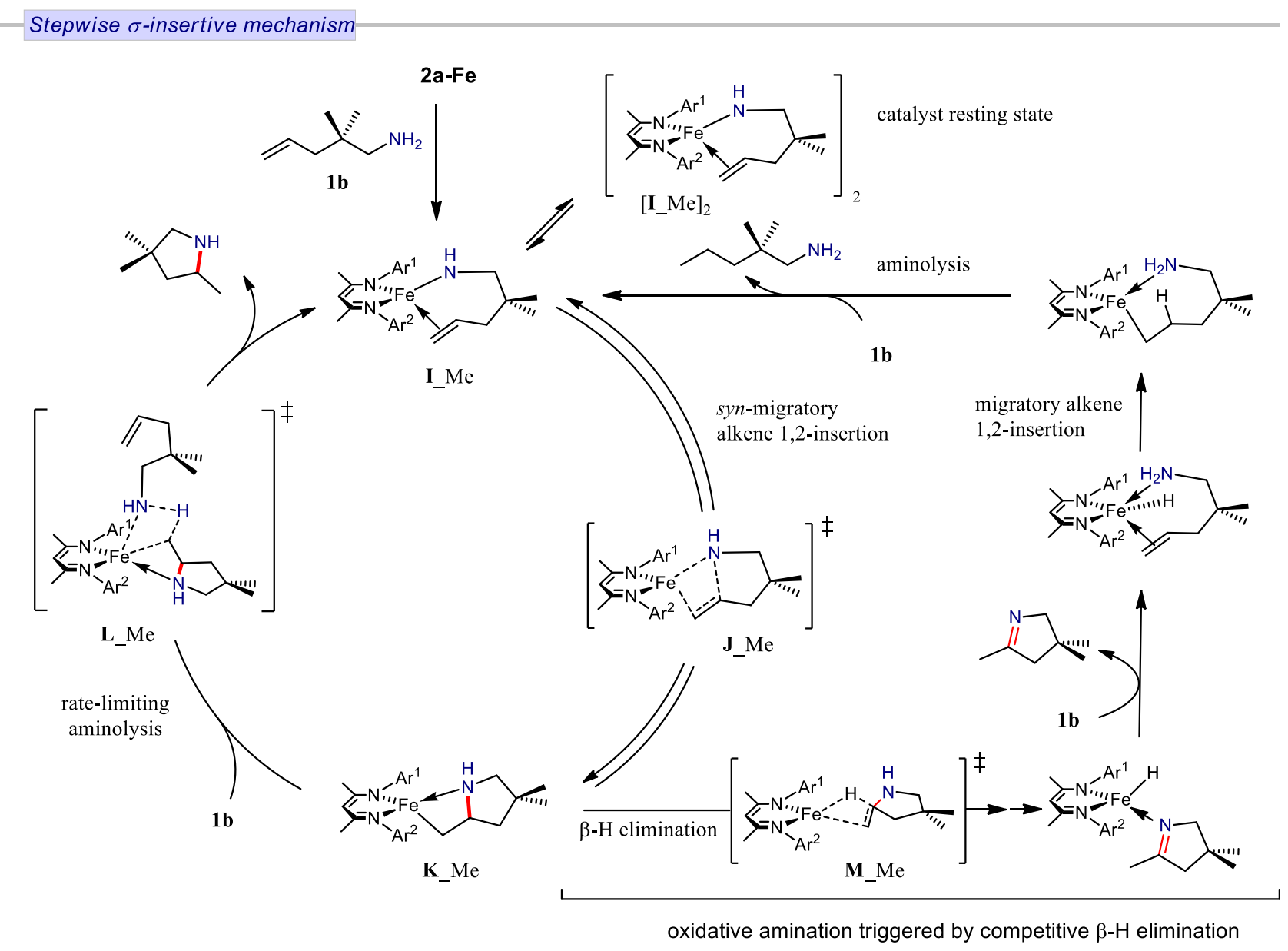

Scheme 8. Cyclohydroamination of primary amines tethered to alkenes catalyzed by $\beta$-diketiminatoiron(II) alkyl complexes $\mathbf{2 a - F e}$ and $\mathbf{2 b - F e}$ and the proposed operating stepwise $\sigma$-insertive mechanism.

On the basis of these accumulated experimental and computational data, a stepwise $\sigma$-insertive mechanism is proposed by the authors as the operating mechanism for the cyclohydroamination reaction catalyzed by $\mathbf{2 a - F e}$ (without cyclopentylamine) as displayed in Scheme 8 (bottom) for substrate 1b. ${ }^{[38]}$ Initial $\sigma$-bond metathesis between $\mathbf{2 a - F e}$ and aminoalkene 1b delivers the catalytically relevant monomeric species I Me, which is in equilibium with its amido dimer $\left[\mathbf{I}_{-}^{-} \mathrm{Me}\right]_{2}$ being likely the catalyst resting state. Subsequent facile and reversible synmigratory-1,2-insertion of the pendant alkene into the $\mathrm{Fe}-\mathrm{N} \sigma$-bond via the transition state structure $\mathbf{J}$ leads to the transient insertive complex K_Me.
Complex K_Me can undergo rate-limiting aminolysis (protodemetalation) of its $\mathrm{Fe}-\mathrm{C} \quad \sigma$-bond with aminoalkene $\mathbf{1 b}$ via transition state structure $\mathbf{L} \mathbf{M e}$, providing the hydroamination product after liberation and regenerating of active catalyst complex I Me (Scheme 8 , bottom) ${ }^{[38]}$ Competitively, insertive alkyl complex K Me can evolve through $\beta-\mathrm{H}$ elimination. In-depth DFT calculations have also been conducted on the mechanistic pathway for rival oxidative amination and have shown that the kinetically viable, competitive $\beta-\mathrm{H}$ elimination pathway features twostate reactivity and takes place through two-spin crossover transition states. ${ }^{[38]}$ This pathway accounts for the formation of oxidative amination products 
(imine and reduced aminoalkene) as side-products according to the elementary steps described in Scheme 8 (bottom). The reaction selectivity originates from the competitive avenues for turnover-limiting protodemetalation and $\beta-\mathrm{H}$ elimination pathways. The selectivity enhancement in presence of additional cyclopentylamine may originate from the participation of this additive in the rate-limiting step that leads to the formation of amido complex $\mathbf{N}$ which is proposed to be in equilibium with the catalytically active species I $\mathrm{Ph}$ (Scheme 9). ${ }^{[5,38]}$ This proposal is based on the independent synthesis of $\mathbf{N}$ which affords similar catalytic efficiency as $\mathbf{2 a - F e}$. The detrimental effect of the additive on the reaction rate may be ascribed to the presence of this equilibrated process. ${ }^{[38]}$

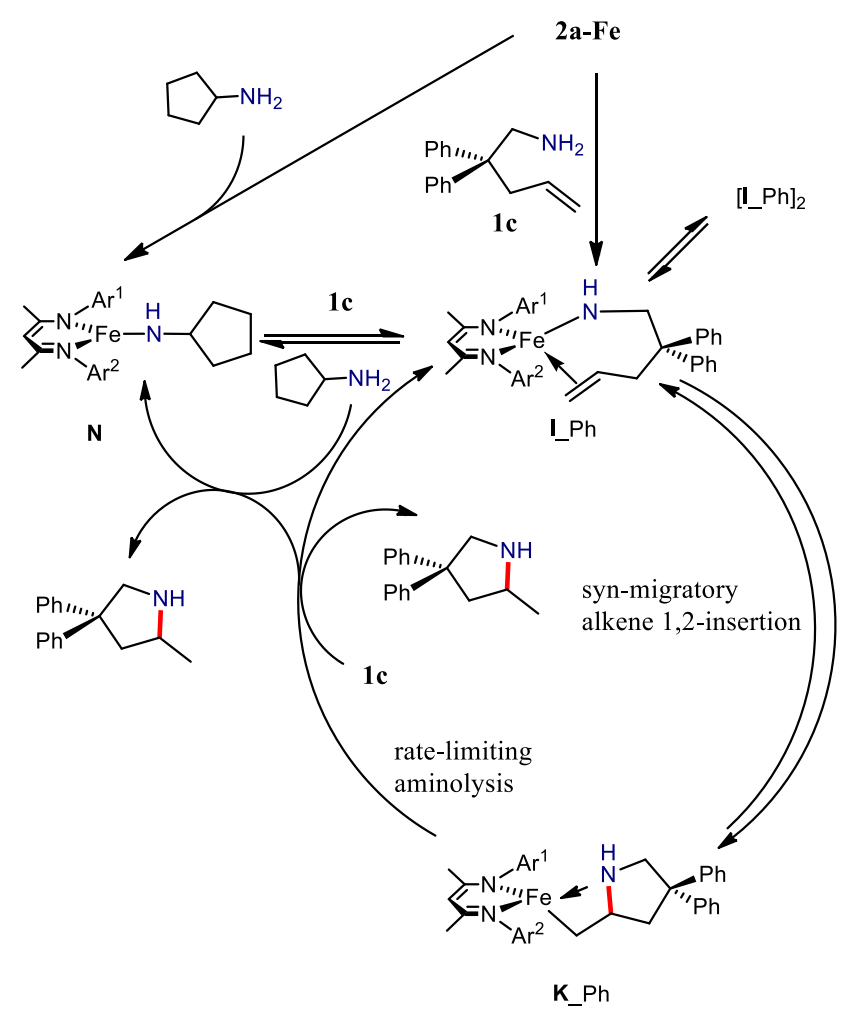

Scheme 9. Proposed mechanism for the hydroamination of primary amines tethered to alkenes catalyzed by $\beta$ diketiminatoiron(II) alkyl complexes 2a-Fe highlighting the putative role of the cyclopentylamine additive.

To bypass this drawback in catalyst reactivity linked to the use of cyclopentylamine additive, an alternative strategy involving rational modification of the $\beta$-diketiminate ligand was recently explored to target high hydroamination selectivity. ${ }^{\left[{ }^{[1]}\right.}$ From their mechanistic DFT investigations ${ }^{[38]}$ and a previous computational study ${ }^{[40]}$ the authors hypothesized that enhancing the steric demands around the metal should disfavor the competitive $\beta$-H elimination pathway and consequently afford higher selectivity in favor of the hydroamination product. Investigations of the catalytic behavior of diverse well-defined $C_{l^{-}}$ symmetric $\beta$-diketiminatoiron(II) alkyl complexes featuring steric and electronic variations on one of the $\mathrm{N}$-aryl substituents of the ligand scaffold highlight that complex $\mathbf{2 b - F e}$ bearing a potentially coordinative ortho-methoxy substituent is a significantly more active and selective catalyst for the cyclohydroamination of primary aminoalkenes (Scheme 8). ${ }^{[41]}$ A hydroamination selectivity of $95 \%$ is reached at $93 \%$ conversion of $\mathbf{1 c}$ after only $250 \mathrm{~min}$ of reaction with $\mathbf{2 b}$-Fe meanwhile a reaction time of up to $48 \mathrm{~h}$ was needed to attain such selectivity with $\mathbf{2 a}-\mathbf{F e} /$ cyclopentylamine. The better efficiency of $\mathbf{2 b}$ Fe may be ascribed to the coordinating ability and/or steric hindrance of the ortho-methoxy substituent as suggested by comparative studies. ${ }^{[41]}$

In 2009, a similar $\sigma$-insertive mechanism by amine activation was proposed as putative operating mechanism for the copper-catalyzed cyclohydroamination of primary and secondary aminoalkenes using $\mathrm{Cu}(\mathrm{Ot}-\mathrm{Bu}) / 4,5$ bis(diphenylphosphino)-9,9-dimethylxanthene (Xantphos) as catalytic system. ${ }^{[7]}$

In 2018, the groups of Hannedouche, Ujaque and Lledós reported that the well-defined low coordinate $\beta$-diketiminatocobalt(II) alkyl 2a-Co as cobalt analogue of 2a-Fe has the ability to catalytically promote the exo-cyclohydroamination of primary aminoalkenes under mild conditions (Scheme10, top). ${ }^{6}$ This report is the first example of cobaltcatalyzed alkene hydroamination with unprotected primary amines. ${ }^{[42]}$ Contrary to the iron catalyst, the introduction of a phenyl ring at the terminal position of the alkene was compulsory to achieve hydroamination reactivity avoiding alkene isomerization as the dominant pathway. This cobalt methodology allows the formation and isolation of diverse gem-disubstituted pyrrolidines and piperidines in satisfactory yields (Scheme10). ${ }^{[6]}$ However, it does not proceed with trisubstituted alkenes or substrates unbiased toward cyclization. ${ }^{[6]}$ The reaction mechanism has been examined by deuteriumlabelling, kinetics and stoichiometric experiments and DFT calculations. From these studies, a novel mechanism distinct to the above iron-catalyzed hydroamination methodology was suggested as the operative pathway by the authors (Scheme 10, bottom). This stepwise non-insertive mechanism features a turnover-limiting nucleophilic attack of the amido moiety of monomeric cobalt(II) complex $\mathbf{O}$ (formed by $\sigma$-bond metathesis between 2a-Co and aminoalkene 1a and coordination of a second molecule of 1a) to the non-coordinated tethered alkene affording the zwitterionic species $\mathbf{P}$ (Scheme 10 , bottom). ${ }^{[6]}$ The catalytically competent species is proposed to be the amidoalkene-aminoalkene cobalt adduct $\mathbf{O}$, which is in rapid equilibrium with its dimer $[\mathbf{O}]_{2}$. The latter was isolated and fully characterized in the solid-state similarly to $\left[\mathbf{I} \_\mathrm{Me}\right]_{2}$. Subsequent rapid proton transfer from the amine group of the coordinated substrate to the methylene anion at the $\mathrm{C}_{2}$ carbon of $\mathbf{P}$ affords neutral species $\mathbf{Q}$ (Scheme 10, 
bottom). Displacement of the hydroamination product by another aminoalkene molecule regenerates the catalytically competent species. DFT calculations highlight no direct interaction between the metal center and the $\mathrm{C}_{2}$ carbon of $\mathbf{P}$, underlining the noninsertive character of the mechanistic proposal. ${ }^{[6]}$

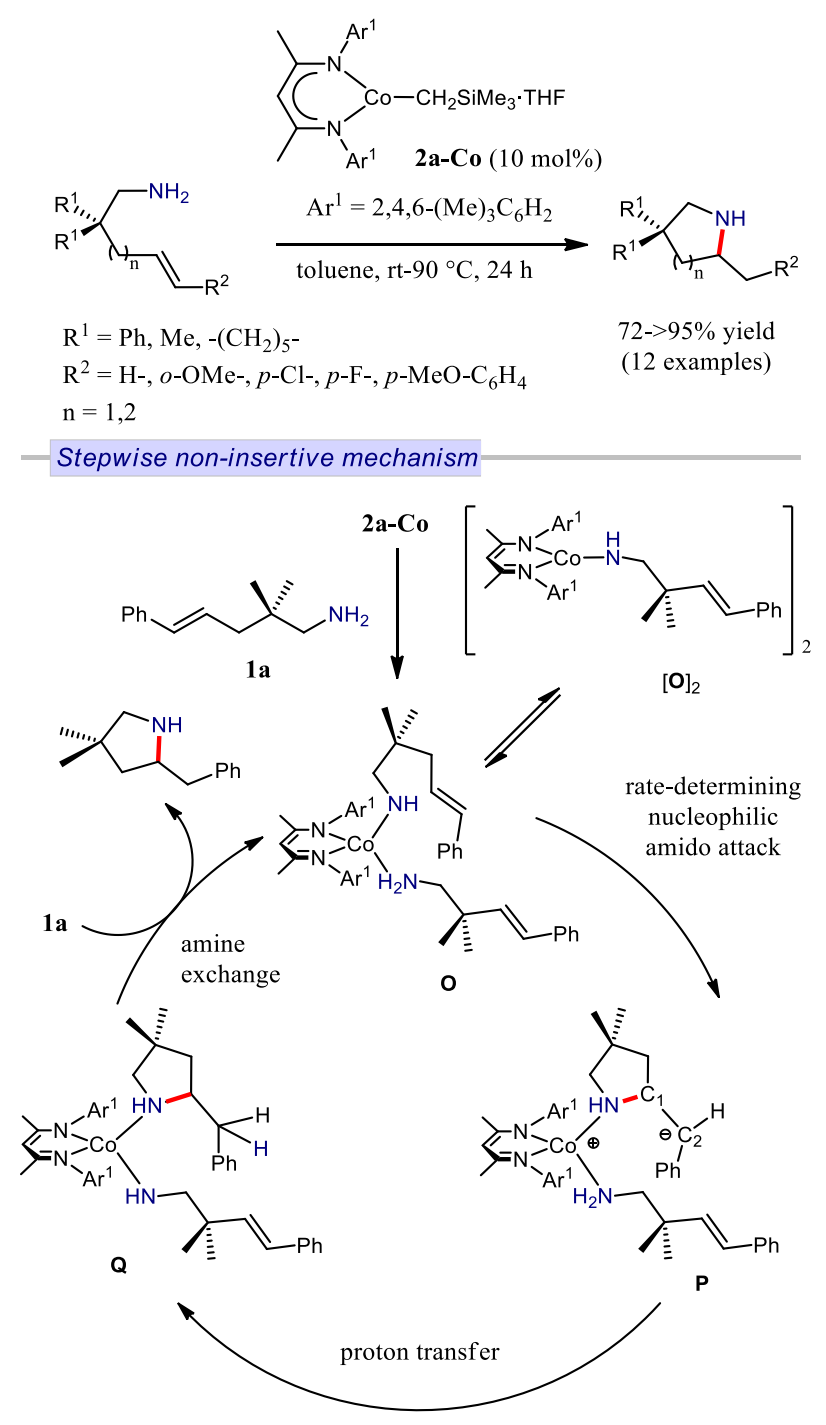

Scheme10. Hydroamination of primary amines tethered to alkenes catalyzed by $\beta$-diketiminatocobalt(II) alkyl complex $\mathbf{2 a - C o}$ and the proposed operating stepwise noninsertive mechanism.

These computational studies reveal that this noninsertive mechanism prevails energetically over alternative operating mechanisms along with the alkene $\pi$-coordination, stepwise $\sigma$-insertive or concerted non-insertive pathways. ${ }^{[6]}$ The experimentally determined second-order rate law $\mathrm{v}=$ $\mathrm{k}[\mathbf{2 a C o}]^{1}[\text { aminoalkene }]^{1}$, syn-stereochemistry of the addition process and activation parameters as well as the no KIE observation are consistent with the proposed stepwise non-insertive mechanism. The stereochemistry of the cyclization was rationalized by the fact that the proton transfer step from $\mathbf{P}$ to $\mathbf{Q}$ is faster than the $\mathrm{C}_{1}-\mathrm{C}_{2}$ bond rotation as demonstrated by DFT calculations (Scheme 10, bottom). ${ }^{[6]}$

\section{Conclusion}

This review gives an overview of the mechanistic investigations conducted on the most relevant advances in the burgeoning area of alkene (formal) hydroamination promoted by earth-abundant $3 \mathrm{~d}$ transition metal catalysts involving iron, cobalt, copper and zinc. This emphasizes the diversity of alkene- and amine-activation strategies encountered to unlock some of the remaining challenging of the field. The fruitful exploitation of the well-developed biphosphine ligated copper-hydride chemistry and the iron hydride hydrogen atom transfer reactions for alkene activation in the context of $\mathrm{C}-\mathrm{N}$ bond formation has led to outstanding breakthroughs in terms of scope, (stereo)selectivities and applicability. However, despite the unquestionable impacts of these formal hydroamination strategies, their global atomand -step efficiency diverge from the direct $\mathrm{N}-\mathrm{H}$ addition on alkenes of classical hydroamination reaction. Successful developments in this direction have been gained by zinc, iron and cobalt catalysts via a more classical alkene $\pi$-coordination or amine deprotonation pathways. These efforts deserve to be underscored and sustained. For the $\mathrm{CuH}-$ and $\mathrm{Fe}$ catalyzed hydroamination proceeding by alkene and amine activation respectively, the understanding of the operating mechanisms have already led to some noteworthy improvements in terms of activity. Undeniably, the insights gathered through these mechanistic studies will trigger further development in catalyst design and one- and two-electron reactivity control in the exciting field of $3 \mathrm{~d}$ metal-catalyzed alkene hydroamination.

\section{Acknowledgements}

Financial support from the CNRS and UnivParis Sud are gratefully acknowledged.

\section{References}

[1] For general, more specialized and early reviews on alkene hydroamination: a) T. E. Muller, K. C. Hultzsch. M. Yus, F. Foubelo, M. Tada, Chem. Rev. 2008, 108, 3795; b) K. D. Hesp, M. Stradiotto, ChemCatChem 2010, 2, 1192; c) J. G. Taylor, L. A. Adrio, K. K. Hii, Dalton Trans. 2010, 39, 1171; d) J. S. Yadav, A. Antony, T. S. Rao, B. V. Subba Reddy, J. Organomet. Chem. 2011, 696, 16; e) N. Nishina, Y. Yamamoto, Hydrofunctionalization, Top. Organomet. Chem., ed. V. P. Ananikov, M. Tanaka, Springer, Berlin Heidelberg, 2013, vol. 43, pp. 115-143; f) J. Hannedouche, E. Schulz, Chem. Eur. J. 2013, 19, 4972; g) W. Li, X. Zhang, A. Reznichenko, A. Nawara-Hultzsch, K. Hultzsch, in Stereoselective Formation of Amines, 
Springer Berlin Heidelberg, 2014, pp. 191-260; h) E. Bernoud, C. Lepori, M. Mellah, E. Schulz, J. Hannedouche, Catal. Sci. Technol. 2015, 5, 2017; i) V. Rodriguez-Ruiz, R. Carlino, S. Bezzenine-Lafollée, R. Gil, D. Prim, E. Schulz, J. Hannedouche, Dalton Trans. 2015, 44, 12029; j) C. Lepori, J. Hannedouche, Synthesis 2017, 49, 1158; k) L. Huang; M. Arndt, K. Gooßen, H. Heydt, L. J. Gooßen, Chem. Rev. 2015, 115, 2596.

[2] a) A. Zulys, M. Dochnahl, D. Hollmann, K.Löhnwitz, J.-S. Herrmann, P. W. Roesky, S. Blechert, Angew. Chem. Int. Ed. 2005, 44, 7794; b) M. Dochnahl, J.-W. Pissarek, S. Blechert, K. Löhnwitz, P. W. Roesky, Chem. Commun. 2006, 3405; c) K. Löhnwitz, M. J. Molski, A. Lühl, P. W. Roesky, M. Dochnahl, S. Blechert, Eur. J. Inorg. Chem. 2009, 1369; d) J.-W. Pissarek, D. Schlesiger, P. W. Roesky, S. Blechert, Adv. Synth.Catal. 2009, 351, 2081; e) M. Dochnahl, K. Löhnwitz, A. Lühl, J.-W. Pissarek, M. Biyikal, P. W. Roesky, S. Blechert, Organometallics 2010,29, 2637; f) J. Jenter, A. Lühl, P. W. Roesky, S. Blechert, J. Organomet. Chem. 2011, 696, 406.

[3] a) A. Mukherjee, T. K. Sen, P. Kr. Ghorai, P. P. Samuel, C. Schulzke, S. K. Mandal, Chem. Eur. J. 2012, 18, 10530; b) A. Mukherjee, T. K. Sen, P. Kr. Ghorai, S. K. Mandal, Organometallics 2013, 32, 7213.

[4] a) R. Blieck, J. Bahri, M. Taillefer, F. Monnier, Org. Lett. 2016, 18, 1482; b) L. A. Perego, R. Blieck, A. Groué, F. Monnier, M. Taillefer, I. Ciofini, L. Grimaud, ACS Catal. 2017, 7, 4253; c) L. A. Perego, R. Blieck, J. Michel, I. Ciofini, L. Grimaud, M. Taillefer, F. Monnier, Adv. Synth. Catal. 2017, 359, 4388.

[5] E. Bernoud, P. Oulié, R. Guillot, M. Mellah, J. Hannedouche, Angew. Chem. Int. Ed. 2014, 53, 4930.

[6] C. Lepori, P. Gómez-Orellana, A. Ouharzoune, R. Guillot, A. Lledós, G. Ujaque, J. Hannedouche, ACS Catal 2018, 8, 4446.

[7] a) H. Ohmiya, T. Moriya, M. Sawamura, Org. Lett. 2009, 11, 2145; b) H. Ohmiya, M. Yoshida, M. Sawamura, Synlett 2010, 2136.

[8] S. Zhu, N. Niljianskul, S. L. Buchwald, J. Am. Chem. Soc. 2013, 135, 15746.

[9] Y. Miki, K. Hirano, T. Satoh, M. Miura, Angew. Chem. Int. Ed. 2013, 52, 10830.

[10] C. B. Huehls, A. Lin, J. Yang, Org. Lett. 2014, 16, 3620.

[11] J. Gui, C. M. Pan, Y. Jin, T. Qin, J. C. Lo, B. J. Lee, S. H. Spergel, M. E. Mertzman, W. J. Pitts, T. E. La Cruz, M. A. Schmidt, N. Darvatkar, S. Natarajan, P. S. Baran, Science 2015, 348, 886.

[12] L. D. Julian, J. F. Hartwig, J. Am.Chem. Soc. 2010, $132,13813$.

[13] K. D. Hesp, S. Tobisch, M. Stradiotto, J. Am.Chem. Soc. 2010, 132, 413.[ [14] a) J. G. Taylor, N. Whittall, K. K. Hii, Org. Lett. 2006, 3561; b) C.
Michon, F. Medina, F. Capet,P. Roussel, F. AgbossouNiedercorn, Adv. Synth. Catal. 2010, 35, 3293.

[15] a) K. Komeyama, T. Morimoto, K. Takaki, Angew. Chem. Int. Ed. 2006, 45, 2938; b) J. Michaux, V. Terrasson, S. Marque, J. Wehbe, D. Prim, J.-M. Campagne, Eur. J. Org. Chem. 2007, 2601; c) X. Cheng, Y. Xia, H. Wei, B. Xu, C. Zhang, Y. Li, G. Qian, X. Zhang, K. Li, W. Li, Eur. J. Org. Chem. 2008, 1929; d) M. S. Jung, W. S. Kim, Y. H. Shin, H. J. Jin, Y. S. Kim, E. J. Kang, Org. Lett. 2012, 14, 6262.

[16] a) C. Deutsch, N. Krause, B. H. Lipshutz, Chem. Rev. 2008, 108, 2916; b) A. J. Jordan, G. Lalic, J. P. Sadighi, Chem. Rev. 2016, 116, 8318.

[17] M. Corpet, C. Gosmini, Synlett 2014, 46, 2258.

[18] For a full historical account on copper-catalyzed formal hydroamination using hydroxylamine esters: $\mathrm{M}$. T. Pirnot, Y.-M. Wang, S. L. Buchwald, Angew. Chem., Int. Ed. 2016, 55, 48.

[19] As an illustration, the original Miura and Hirano combination is ineffective for $c i s-\beta$-substituted styrenes and terminal aliphatic alkenes in contrast to the original Buchwald combination, see references 8-9.

[20] a) S. Zhu, S. L. Buchwald, J. Am. Chem. Soc. 2014, 136, 15913; b) N. Niljianskul, S. Zhu, S. L. Buchwald, Angew. Chem. Int. Ed. 2015, 54, 1638; c) D. Nishikawa, K. Hirano, M. Miura J. Am. Chem. Soc. 2015, 137, 15620.

[21] a) Y. Yang, S.-L. Shi, D. Niu, P. Liu, S. L. Buchwalc, Science, (Washington, D. C.) 2015, 349, 62; b) D. Niu, S. L. Buchwald, J. Am. Chem. Soc. 2015, 137, 9716; c Y. Xi, T. W. Butcher, J.; Zhang, J. F. Hartwig, Angew. Chem. Int. Ed. 2016, 55, 776.

[22] Most of the studies conducted on internal alkenes were conducted on $(E)$-isomers. It was reported on an isolated example that a (Z)-1,2-dialkylsubstituted alkene (bearing an electron-withdrawing group substituted oxygen at the homoallylic position) undergoes hydroamination in low yield and with low enantioselectivity, see reference $21 \mathrm{c}$.

[23] a) J. Bandar, M. T. Pirnot, S. L. Buchwald, J. Am. Chem. Soc. 2015, 137, 14812; b) G. Lu, R. Y. Liu, Y. Yang, C. Fang, D. S. Lambrecht, S. L. Buchwald, P. Liu. J. Am. Chem. Soc. 2017, 139, 16548.

[24] S. Tobisch, Chem. Eur. J. 2016, 22, 8290.

[25] J.-T. Issenhuth, F.-P. Notter, S. Dagorne, A. Dedieu, S. Bellemin-Laponnaz, Eur. J. Inorg. Chem. 2010, 2010, 529.

[26] A. A. Thomas, K. Speck, I. Kevlishvili, Z. Lu, P. Liu, S. L. Buchwald, J. Am. Chem. Soc. 2018, 140, 13976.

[27] a) H. Wang, J. C. Yang, S. L. Buchwald, J. Am. Chem. Soc. 2017, 139, 8428. For applications in tandem/relay catalysis processes: b) S.-L. Shi; S. L. Buchwald, Nat. Chem. 2015, 7, 38; c) S.-L. Shi, Z. L. Wong, S. L. Buchwald, Nature 2016, 532, 353; d) S. Zhu, N. Niljianskul, S. L. Buchwald, Nat. Chem. 2016, 8, 144. 
[28] a) S. Ichikawa, S. Zhu, S. L. Buchwald, Angew. Chem. Int. Ed. 2018, 57, 8714; b) S. Guo, J. C. Yang, S. L. Buchwald, J. Am. Chem. Soc. 2018, 140, 15916; c) Y. Ye, S.-T. Kim, J. Jeong, M.-H. Baik, S. L. Buchwald, J. Am. Chem. Soc. 2019, 141, 3901; d) S. Ichikawa, X.-J. Dai, S. L. Buchwald, Org. Lett. 2019, 21, 4370.

[29] J. C. Lo, Y. Yabe, P. S. Baran, J. Am. Chem. Soc. 2014, 136, 1304; b) J. C. Lo, J. Gui, Y. Yabe, C.-M. Pan, P. S. Baran, Nature 2014, 516, 343.

[30] a) E. G. Janzen, Acc. Chem. Res. 1971, 4, 31; b) K. Kato, T. Mukaiyama, Chem. Lett. 1992, 21, 1137; c) E. K. Leggans, T. J. Barker, K. K. Duncan, D. L. Boger, Org. Lett. 2012, 14, 1428.

[31] For a presentation of this work: M. Villa, A. J. von Wangelin, Angew. Chem. Int. Ed. 2015, 54, 11906.

[32] For a background account on iron-mediated radical hydrofunctionalization of alkenes: S. W. M. Crossley, C. Obradors, R. M. Martinez, R. A. Shenvi, Chem. Rev. 2016, 116, 8912 .

[33] H. Nakazawa, M. Itazaki, Top. Organomet. Chem. 2011, 33, 27.

[34] a) J. C. Lo, D. Kim, C.-M. Pan, J. T. Edwards, Y. Yabe, J. Gui, T. Qin, S. Gutiérrez, J. Giacoboni, M. W. Smith, P. L. Holland, P. S. Baran, J. Am. Chem. Soc. 2017, 139, 2484; b) D. Kim, S. M. W. Rahaman, B. Q. Mercado, R. Poli, P. L. Holland, J. Am. Chem. Soc. 2019, 141, 7473 .

[35] The improve activity with monoalkoxysilane may originate from a faster rate of generation of the reactive iron hydride, see reference 29 for details.

[36] a) C. Obradors, R. M. Martinez, R. A. Shenvi, J. Am. Chem. Soc. 2016, 138, 4962; b) K. Zhu, M. P. Shaver, S. P. Thomas, Chem. Asian J. 2016, 11, 977; c) K. Zhu, M. P. Shaver, S. P. Thomas, Chem. Sci. 2016, 7, 3031.

[37] a) H. Andres, E. Bominaar, J. M. Smith, N. A. Eckert, P. L. Holland, E. Münck, J. Am. Chem. Soc. 2002, 124, 3012; b) T. J. J. Sciarone, A. Meetsma, B. Hesssen, J. H. Teuben, Chem. Commun. 2002, 1580; c) J. M. Smith, R. J. Lachicotte, P. L. Holland, Organometallics 2002, 21, 4808; d) J. Vela, J. M. Smith, R. J. Lachicotte, P. L. Holland, Chem. Commun. 2002, 2886; e) J. Vela, S. Vaddadi, T. R. Cundari, J. M. Smith, E. A. Gregory, R. J. Lachicotte, C. J. Flaschenriem, P. L. Holland, Organometallics 2004, 23, 5226; f) T. J. J. Sciarone, A. Meetsma, B. Hessen, Inorg. Chim. Acta 2006, 359, 1815.

[38] C. Lepori, E. Bernoud, R. Guillot, S. Tobisch, J. Hannedouche, Chem. Eur. J. 2019, 25, 835.

[39] a) J. F. Dunne, D. B. Fulton, A. Ellern, A. D. Sadow, J. Am. Chem. Soc. 2010, 132, 17680; b) K. Manna, M. L. Kruse, A. D. Sadow, ACS Catal. 2011, 1, 1637; c) D. C. Leitch, R. H. Platel, L. L. Schafer, J. Am. Chem. Soc. 2011, 133, 15453; d) B. Liu, T. Roisnel, J.-F. Carpentier, Y. Sarazin, Angew. Chem. Int. Ed. 2012, 51, 4943; e) K. Manna, W. C. Everett, G. Schoendorff, A.
Ellern, T. L. Windus, A. D. Sadow, J. Am. Chem. Soc. 2013, 135, 7235 .

[40] S. M. Bellows, T. R. Cundari, P. L. Holland, Organometallics 2013, 32, 4741.

[41] C. Lepori, R. Guillot, J. Hannedouche, Adv. Synth. Catal. 2019, 361, 714.

[42] For a cobalt-catalyzed cyclohydroamidation with $\mathrm{N}$ protected aminoalkenes: H. Shigehisa, N. Koseki, N. Shimizu, M. Fujisawa, M. Niitsu, K. Hiroya, J. Am. Chem. Soc. 2014, 136, 13534. 


\section{REVIEW}

Alkene Hydroamination via Earth-Abundant Transition Metal ( $\mathrm{Fe}, \mathrm{Co}, \mathrm{Cu}$ and $\mathrm{Zn}$ ) Catalysis: A Mechanistic Overview

Adv. Synth. Catal. Year, Volume, Page - Page

Pierre Colonna, Sophie Bezzenine, Richard Gil and Jérôme Hannedouche*

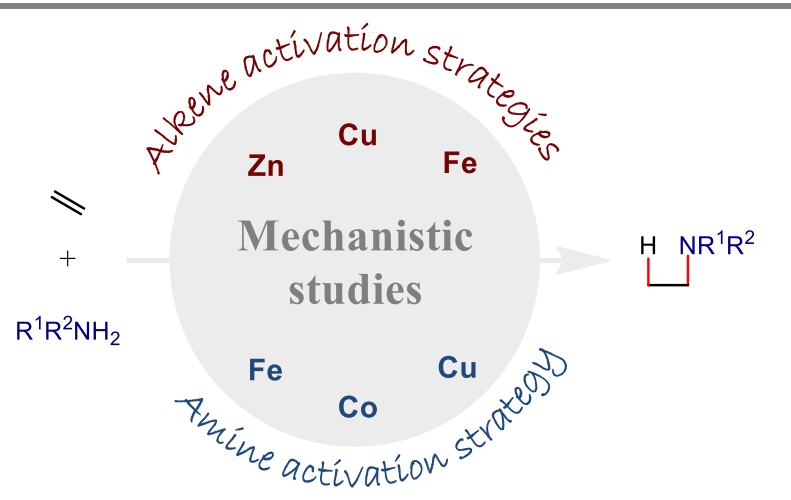

